\title{
Incursão em pista: um risco potencial, atual e crescente nas operações
}

\section{Runway incursion: a growing, actual and potential risk to operations}

\author{
Wilber Campos Fonseca', Humberto César Machado² \\ Bacharelando do 7 o período do curso de Ciências Aeronáuticas, da PUC-GO; Piloto. Autor premiado pela apresentação do projeto "Compreendendo um Veículo Lançador \\ de Satélites" na Sociedade Brasileira para o Progresso da Ciência (SBPC), em evento realizado na Unicamp-SP. Autor premiado em 1임a pela apresentação do artigo \\ "Incursão em pista: um problema atual e crescente", na categoria Fórum de Pesquisa, da Semana de Ciência e Tecnologia da PUC-GO. <wilbercampos@ hotmail.com> \\ Doutor e Mestre em Psicologia pela PUC-GO (2013, 2006); Especialista em História pela UFG (2002); Graduado em Filosofia pela mesma universidade (1996) \\ Elemento Credenciado Fatores Humanos e Prevenção de Acidentes Aéreos pelo Centro de Investigação e Prevenção de Acidentes Aeronáuticos (Cenipa). \\ Professor da UNIFAN e da PUC-GO. <humberto.cesar@hotmail.com>.
}

\begin{abstract}
RESUMO
Com a elevada demanda no tráfego aéreo, as incursões (acidentes) em pista têm aumentado significativamente no mundo. Considerada como uma das mais graves ameaças à segurança operacional faz-se necessário saber o posicionamento das autoridades aeronáuticas em relação ao assunto, as medidas preventivas já implantadas e as que estão sendo pensadas para o futuro. $\mathrm{O}$ atual perfil dos pilotos é complexo e exige uma boa qualificação. No Brasil, a adoção do SMS (Sistema de Gerenciamento da Segurança), de novas tecnologias e a consciência situacional são meios de mitigar esse problema. Como o homem é o primeiro e principal elemento para a prevenção de tragédias, sem a sua cooperação todo trabalho é impensável. Assim, o objetivo principal deste artigo é apresentar informações técnicas e científicas atualizadas para propiciar um melhor entendimento acerca das peculiaridades que envolvem as preocupantes incursões em pista. Além disso, serão listadas algumas das mais modernas medidas tecnológicas que estão sendo implementadas como meios de prevenção de tais ocorrências.
\end{abstract}

PALAVRAS-CHAVE: Incursão em pista; Prevenção; Tecnologia; SMS; Contribuintes; Brasil

\section{ABSTRACT}

With the elevated air traffic demand, runway incursions (accidents) have significantly increased around the world. Considered as one of the most serious threat to operational security, in the matter it's necessary to know the aeronautical authorities opinion related to the issue, the prevention methods already implemented and others are being developed for the future. The present pilot's profile is complex, and demands a good qualification. In Brazil, the adoption of SMS for new technologies and situational awareness are methods to reduce this problem. As human being is the first and main element for tragedy prevention, without its cooperation all this work is unable. This article's main goal is to present updated technical and scientific information to provide a better knowledge about the peculiarities which involves the worrying runway incursions. Besides, it will be listed some of the most modern technological measures that are being implemented as a means for preventing these occurrences.

KeYwORDS: Runway incursion; Prevention; Technologies; SMS; Contributing; Brazil

Pontifical Catholic University of Rio Grande do Sul Porto Alegre, RS, Brazil

Editor

Thaís Russomano

Microgravity Centre PUCRS, Brazil

Executive Editor

Rafael Reimann Baptista

Faculdade de Educação Física e Ciências do Desporto, PUCRS, Brazil

e-ISSN: 2179-703X

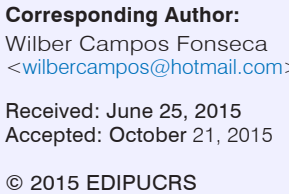

(C) 2015 EDIPUCRS

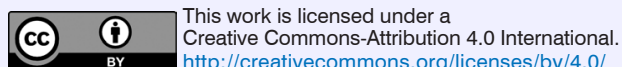




\section{INTRODUÇÃO}

Com a grande e crescente demanda das atividades aéreas, em um curto espaço de tempo, a frota de aeronaves vem aumentando significativamente. Como consequência, os aeroportos se tornam cada vez mais movimentados com o passar de cada ano e a preocupação com as operações de pouso e decolagem também se intensificam. Por isso, é preciso dar total atenção para as ocorrências de incursão em pista e lembrar que o trabalho em equipe é de fundamental importância, pois ele aponta o mesmo problema visto de outro ângulo.

Nesse sentido, vale lembrar que o maior acidente aéreo da história mundial da aviação, uma incursão em pista entre duas aeronaves, ocorreu no Aeroporto de Los Rodeos, na Ilha de Tenerife, em 27 de março de 1977, no qual morreram 583 passageiros e tripulantes. Feitas as investigações a respeito das causas desse acidente, por cerca de 70 investigadores de diversos países, concluiu-se que um significativo número de falhas latentes e ativas provocou a sua ocorrência; esse fato ficou conhecido como o maior e mais terrível acidente do século XX. Contudo, segundo Ivan Sant'anna (1), a causa da colisão entre as aeronaves foi o início inesperado da decolagem do KLM (empresa aérea), sem autorização concedida pela torre de controle, enquanto o Pan Am (outra empresa aérea) ainda estava na pista taxiando.

Após o acidente de Tenerife, várias alterações no sistema aeronáutico foram feitas, como mudanças de hierarquia nos procedimentos de cabine, que são adotadas somente depois de um acidente. Decisões críticas de voo devem ser tomadas com a concordância de todos os membros da tripulação técnica; esta não é mais uma soberania apenas dos pilotos em comando. A análise feita de acidentes (Toda ocorrência relacionada com a operação de uma aeronave, ocorrida entre o período em que uma pessoa nela embarca com a intenção de realizar um voo, até o momento que desembarca e durante o qual, pelo menos uma das situações ocorra: lesão grave ou morte, aeronave com grandes danos ou falhas estruturais, aeronave considerada desaparecida) e incidentes (Toda ocorrência associada à operação de uma aeronave que não chegue a se caracterizar como um acidente aeronáutico, mas que afete ou possa afetar a segurança da operação) revelam que falhas no controle de tráfego aéreo, deficiência no gerenciamento da cabine de comando e falta de infraestrutura aeroportuária são os principais fatores contribuintes para a sua consumação. É importante ressaltar que um acidente aeronáutico não ocorre apenas por um motivo isolado, há sempre a junção de vários fatores que resultam em um sinistro.

A automação nas atuais aeronaves é de fundamental importância para elas, pois gera economia, agilidade nas interpretações de dados, além de ser precisa. Com o seu elevado grau de tecnologia, cria-se um novo perfil para os aviadores: atenção, rápida interpretação, treinamento e intenso monitoramento da elevada quantidade de dados disponíveis na cabine de uma aeronave.

O atual perfil profissional dos pilotos é complexo e exige boa formação, com uma fácil adaptação a novas tecnologias, agilidade, conhecimento e preparo para enfrentar as situações de emergência. Dessa forma, as escolas de treinamento procuram se adaptar à constante mudança de tecnologias, buscando levar para os futuros pilotos o conhecimento necessário para a sua formação, através de treinamento para tomada de decisões, uso de computadores e simuladores, enfim, com o uso da tecnologia necessária, ainda que não seja possível o treinamento prático em universidades.

Com base no exposto, faz-se necessário saber como o Brasil está tratando dessa complicação. Isto é, com a adoção de programas para mitigar problemas relacionados à aviação, à consciência situacional e ao homem como principal meio de prevenção das incursões em pista. $O$ posicionamento das autoridades aeronáuticas também é de fundamental importância para entender, discutir, divulgar e buscar soluções para um problema que, se não for atenuado, trará graves consequências futuras, dado o aumento da aviação mundial.

\section{Incursão em pista, uma corrente ascendente e de prazo indeterminado}

Atualmente, constata-se uma situação intrigante nos aeroportos, nem sempre fácil de ser controlada. Isso porque aeronaves, veículos e pessoas precisam se relacionar de uma forma muito harmônica para que os objetivos próprios de cada um sejam alcançados. Somam-se a isso os pousos e decolagens na mesma pista em que profissionais da área precisam ingressar, para fazer manutenção, ou vistoria, por exemplo. Essas questões, vale reafirmar, se devem ao significativo aumento da atividade aérea, que, além de elevar o número de aeronaves com melhor desempenho, e de elas serem maiores para acomodar uma maior quantidade de pessoas a bordo, provocou também o surgimento de novos problemas que até então eram desconhecidos e não apresentavam um risco de nível tão elevado quanto no seu início. Assim, como estes problemas 
podem acontecer em todos os países e em todos os aeroportos, é necessário mostrar as ferramentas úteis para reduzir as probabilidades de sua futura ocorrência.

Apesar da constante evolução da tecnologia, o homem ainda é um ser limitável, que, mesmo com o passar do tempo, pode cometer os mesmos erros; no entanto, pode-se destacar que em parte absoluta das incursões em pista, dentre os seus fatores contribuintes, um deles está entre o sidestick (controle de dirigibilidade) e a poltrona. Incursão em pista é uma peculiaridade da aviação, que necessita cada dia mais conhecer os diversos pontos de vista do sistema aeronáutico. Para todos os profissionais envolvidos na aviação, é preciso treinamento e estudos detalhados constantes sobre prevenção de incursão em pista.

\subsection{Conceito de incursão em pista}

A Organização Internacional de Aviação Civil (ICAO), em 25 de novembro de 2004, por meio da publicação de uma emenda ao PANS - ATM (Gestão do Tráfego Aéreo), documento 4444, passou a definir o termo incursão em pista como "qualquer ocorrência em um aeródromo envolvendo a presença incorreta de uma aeronave, de um veículo ou de uma pessoa na zona protegida (considera-se como zona protegida, a própria pista ou a parte nivelada de uma faixa de pista, a zona livre de obstáculos na área de manobra, principalmente nos pontos de espera e nas vias destinadas aos veículos terrestres) de uma superfície designada para pousos ou decolagens de aeronaves" (2); caso um deles ingressar na pista, além das consequências, será considerada uma incursão em pista.

\section{Fatores contribuintes para uma incursão em pista}

Segundo a Organização Europeia para a Segurança da Navegação Aérea (3), quando um estudo rigorosamente detalhado sobre o tema é realizado, podem ser identificados mais de 400 fatores que contribuem com uma incursão em pista. Esse tipo de análise tem proporcionado às autoridades de segurança operacional o conhecimento de fatores persistentes no acidente ou incidente, que se agrupam em três campos: a cabine de comando da aeronave, a infraestrutura aeroportuária e, por último, o controle de tráfego aéreo.

\subsection{Cabine de comando da aeronave}

Diversos elementos dentro da cabine de comando de uma aeronave, que desencadeiam uma incursão em pista, estão ligados ao fator humano (4). Por exemplo, a comunicação entre o controlador de voo ou empresa e o piloto, durante o táxi ou a decolagem, é motivo para a falta de conscientização com o ambiente externo da aeronave, que leva o piloto a desconcentrar-se e não perceber pequenos obstáculos durante as operações. Vale destacar que a configuração da aeronave deve ser feita antes do seu deslocamento. Quando necessário, o piloto deve pedir progressivamente instruções de táxi. Além disso, o ingresso na pista de táxi, decolagem ou no pátio, sem a observação completa do ambiente externo, em virtude da elevada quantidade de informações dentro da cabine, e conversas desnecessárias, em uma situação que requer total atenção da tripulação, são outros fatores preocupantes relacionados à cabine de comando durante uma operação (5).

Um planejamento deficiente do voo, em que o piloto deixa de consultar todas as informações inerentes à operação que vai realizar, pode ocasionar o ingresso em pistas erradas, principalmente se o local estiver com más condições de visibilidade, mal sinalizada ou com congestionamento. A baixa quantidade de tráfego e a familiaridade com aeródromos que não possuem serviço de controle de tráfego aéreo levam alguns pilotos a não utilizarem a fonia para informar sua posição ou fazem isso na frequência errada. A pouca experiência de pilotos os deixa intimidados em questionar os órgãos de controle e o comandante da aeronave quanto a orientações recebidas - se a posição está correta, para qual lado deve ser a curva - mesmo quando estão inseguros com relação a qual caminho seguir. Todo cotejamento (em fraseologia, repetição total das informações recebidas) requer uma confirmação do órgão de controle. Além disso, os pilotos, nas autorizações de cruzamento, pouso e decolagem, devem incluir o indicativo da pista em seus cotejamentos.

Nesse sentido, o piloto deve estar seguro quanto às orientações de procedimentos necessários durante a execução de seu trabalho; saber sempre onde está, para onde vai e por onde; estabelecer uma sequência mental das atividades do aeroporto; ter sempre certeza de que toda a comunicação foi bem entendida; ficar atento quando houver outra aeronave com código de chamada semelhante; ter muita atenção, caso seja autorizado a 'alinhar e manter', ao movimento das aeronaves na aproximação; se a espera ultrapassar 90 segundos, é preciso questionar o controle sobre a estimada de espera (atitude que não pode ser esquecida de forma nenhuma); ficar atento à fraseologia em inglês e às suas peculiaridades quando estiver operando sob regras de voo FAA ou ICAO; conhecer e seguir os procedimentos corretos para o caso de falha de comunicação; utilizar sempre o diagrama do aeródromo quando estiver operando em localidades 
desconhecidas; e ler atentamente o NOTAM (Aviso aos aero-navegantes) dos aeroportos de saída, destino e alternativa. Nunca é demais lembrar que a elaboração de programas educacionais voltados à conscientização dos pilotos para a comunicação correta de sua posição, quando em aeródromos não controlados, é de suma importância para garantir a segurança das operações de voo.

\subsection{Infraestrutura aeroportuária}

A expansão dos aeroportos para atender à elevada demanda do tráfego aéreo, se comparado com antes (Século XX), tornou-o muito mais complexo. Se a complexidade do aeródromo provocou o aumento do nível de risco para incursões em pista, podemse adotar novos padrões, que não são previstos, não são vedados. As autorizações são necessárias para o ingresso e o movimento nas áreas dos aeroportos. De acordo com uma recomendação do Eurocontrol (3), é necessário que o número de motoristas autorizados a dirigir na área operacional se restrinja ao mínimo possível, para assim, evitar conflito com as aeronaves. No Brasil, segundo a ICA 3-2 - Programa de Prevenção de Acidentes Aeronáuticos da Aviação Civil Brasileira -, emitida pelo Centro de Investigação e Prevenção de Acidentes Aeronáuticos (CENIPA), as incursões em pistas causadas por pedestres são as que mais se destacam (6).

A falta de sinalização (ou a sinalização deficiente), em áreas de maior índice de perigo, pode levar o piloto tanto a não tomar cuidados simples e necessários para a segurança quanto conduzi-lo a uma execução contrária ao previsto. Sinalizações progressivas próximas a pontos críticos do aeroporto, de maiores índices de ocorrências de incidentes, favorecem um despertar maior da atenção dentro da cabine de comando. A familiarização com o aeroporto também é um fator crucial, pois pode criar uma zona de conforto que, por consequência, provoca a falta de comunicação e o descumprimento de regras básicas em uma operação de solo. $\mathrm{O}$ déficit na interpretação de cartas de aeródromos, dados desatualizadas, a meteorologia, as cartas de subida, entre outras questões, também deixam a desejar quanto à adequada segurança.

Além disso, o uso de múltiplos pontos de entrada na pista principal aumenta sobremaneira o risco de incursões, pois haverá mais locais de conflito, assim como o aumento da carga de trabalho dos controladores, que é um desafio para a consciência dos pilotos. A dificuldade da administração aeroportuária, em manter sua cerca patrimonial, é outro fator que tem gerado elevado número de ocorrências, em razão da entrada de pessoas na área operacional. Assim, é necessária uma fiscalização mais rigorosa em volta dos aeroportos. Para um maior grau de consciência dos pilotos, as placas de sinalização das pistas de táxi, em ambos os lados, são necessárias, visto que proporcionam uma maior clareza e chamam mais a atenção da tripulação para saber em qual taxiway está ingressando.

\subsection{Controle de tráfego aéreo}

As reduções da qualidade e da precisão da comunicação entre o controle de tráfego aéreo e os outros atores do cenário operacional de um aeroporto determinam um potencial considerável de risco nas operações. O esquecimento do controlador de voo em uma determinada autorização; a falta de atenção dos controladores ao correto cotejamento emitido pelos pilotos; o uso deficitário da fraseologia-padrão tanto dos controladores quanto dos pilotos; as semelhanças entre os prefixos das aeronaves; a abreviação no cotejamento e as informações úteis e importantes; o grande volume no controle de aeronaves por controladores; a falta de humildade de ambas as partes, solicitando um novo cotejamento, entre outros aspectos, são os principais fatores que influenciam a qualidade do tráfego aéreo e que podem levar a uma catástrofe na aviação (7).

Um estudo dirigido pela Flight Safety Foundation (8) revela que há maior incidência de incursões em pista nos primeiros cinco minutos após o controlador assumir a posição ocupada por outro. Esse fato ocorre porque o segundo controlador ainda está com um baixo nível de consciência situacional e não recebeu todas as informações relevantes. De acordo com o Eurocontrol (3), a atitude de um controlador, ao falar rápido, buscando economia de tempo e achando que está mostrando eficiência, dobra as chances de erros de cotejamento. Com essa preocupação, emitiu-se a recomendação de que é aconselhável que o controlador mantenha um ritmo que não exceda 100 palavras por minuto. Com relação à fraseologia, verifica-se que problemas relativos à proficiência no uso da língua inglesa têm acarretado casos de incursão, em virtude de entendimentos errôneos na comunicação entre pilotos e controladores.

O controlador deve evitar a autorização para 'alinhar e manter', em condições de baixa visibilidade ou em operações noturnas; desconsiderar, sempre que possível, autorizações para decolagens de interseções; conhecer e adotar as estratégias existentes na ICA 63-21 - Programa para Prevenção de Ocorrências de Incursões em Pista no ATS, emitida pelo Departamento de Controle do Espaço Aéreo. Outra fonte de erro, segundo o Runway Safety Guidance, é a emissão de 
instruções de táxi imediatamente após o pouso da aeronave, situação na qual a carga de trabalho dos pilotos ainda é elevada. O decréscimo do nível de consciência situacional, quando há diminuição da visibilidade ou aumento do volume de tráfego aéreo, torna-se mais fácil, havendo tendência ao aumento da fadiga e, consequentemente, à desatenção no gerenciamento dos tráfegos.

Controladores olham para as aeronaves quando emitem as autorizações de decolagem, pouso ou táxi sem fazer a varredura visual da pista. Para evitar incidentes, eles devem ser treinados para observar cuidadosamente as pistas, assegurando que estejam livres de obstruções, antes de autorizar o cruzamento, o pouso ou a decolagem (7). Os veículos que necessitem transitar pela área de manobras estarão sujeitos à autorização de uma posição operacional da torre de controle do aeródromo. Quando o controlador perceber que há pouca familiarização com os termos utilizados ou que há o descumprimento das autorizações emitidas para o trânsito de um veículo na área de manobras, imediatamente deve comunicar o fato ao setor responsável pela Segurança Operacional do aeródromo, para que sejam tomadas as providências decorrentes; carece também efetuar o registro do evento. Ainda, é preciso haver um treinamento dos operadores, enfatizando a utilização da fraseologia aeronáutica prevista nas normas vigentes.

\section{Tecnologia e incursão em pista}

A evolução tecnológica na aviação mostra que o homem é constantemente bombardeado por uma infinidade de novas tecnologias. É de fundamental importância, para ele, conhecê-las, por apresentar novos recursos e conceitos na aviação mundial; além disso, como podem ter um elevadíssimo grau de complexidade e informações, se não forem enfatizados no novo homem da aviação, podem vir a causar grandes problemas (9).

O novo perfil dos aviadores não exige apenas os preceitos do passado, mas o compartilhamento do conhecimento; a constante atualização, por meio do estudo das novas tecnologias; o trabalho em equipe; e o bom gerenciamento de processos, por exemplo. Nesse sentido, é bom lembrar que, muitas vezes, o ensinamento passado, e talvez defasado, exerce influência de forma expressiva na facilidade ou não de adaptação às novas tecnologias, desenvolvidas com muita rapidez.

Para o iniciante na aviação, no atual contexto, há várias formas de qualificação profissional, que ampliam o seu campo de entendimento e atuação. Hoje a comunidade aeronáutica pode contar com os cursos de Ciências Aeronáuticas, por exemplo, que visam formar não apenas um mero operador de aeronaves (cada vez mais modernas), mas sim, um profissional com mais conhecimento e ampla visão de mundo. Entretanto, infelizmente nas universidades ainda não há a formação prática para os pilotos, essa função é deixada para aeroclubes e companhias. Se, por um lado, as tão avançadas e novas tecnologias facilitam e tornam mais seguros os sistemas das aeronaves e sua operação, por outro, exigem dos pilotos um ainda que básico conhecimento de Ciência da Computação, para que tenham sempre mais informações.

O processo de formação dos futuros profissionais tornou-se mais complexo e longo, exigindo o emprego das mais novas e diversas tecnologias para o treinamento dos pilotos, o que, consequentemente, gera maiores custos. Simuladores, computadores, estudos físicos e salas especiais criam um universo mais dinâmico, são meios importantes de aprimoramento para a aviação mundial; portanto, as universidades passam a fazer parte integrante e única nesse novo caminho e cenário tecnológico.

\section{Meios alternativos de prevencão de acidentes}

Com a análise dos principais fatores contribuintes para uma incursão em pista, foram feitos diversos estudos sobre o tema com o intuito de padronizar e aperfeiçoar os procedimentos de cabine juntamente com os procedimentos de tráfego de aeronaves. Assim, medidas preventivas foram tomadas, como: 1) aumentar a separação do ponto de espera, para que haja uma maior margem de segurança para as aeronaves que arremetem e que estão no planeio vindo para pouso; 2) proibir o uso do celular na cabine ou as conversas sobre assuntos que não se referem ao voo - meios de segurança na decolagem e no pouso; e 3) evitar autorizações condicionais. Além dessas medidas, temse como objetivo geral desenvolver novas tecnologias que possam elevar o grau da consciência situacional dos pilotos, motoristas e controladores de voo, bem como alertá-los, visto que são eles que desfrutam do sistema.

Estas são medidas simples, de baixo custo e criativas, quando pensamos em marcações e sinalizações de pistas, que são de total contribuição para mitigar as incidências de incursões. Vale ressaltar que, com a implementação desses meios, as ocorrências de incursões em pista mais severas (categorias A e B), resultantes de uma aeronave que cruzou a pista durante a decolagem de outra, sofreram uma queda de mais de 
20\% (10). Também podem ser citadas, como formas preventivas de imprevistos, o checklist para operadores de carros e viaturas, e a sua inspeção, antes do seu acionamento e do conhecimento da carta do aeroporto.

Deve-se criar um hábito preventivo, mas não se pode esquecer de que mudar costumes passados também é necessário. Há, ainda, a necessidade de reportar todas as ocorrências, mesmo que não tenham causado danos, pois favorecem a criação de um banco de dados acerca desses fatos. Consideráveis números das incursões em pista ocorrem durante o dia, com boas condições meteorológicas: céu claro, boa visibilidade; isso mostra que, durante as más condições de tempo, o piloto se torna mais atento e que, durante ótimas condições de operação, ele deixa a desejar, possibilitando assim o erro.

Também merecem destaque os equipamentos utilizados para a prevenção de acidentes. $O$ Enhanced Flight Vision System - Sistema de Realce de Visão em Voo (EFVS) - é um equipamento tecnológico que possibilita aos pilotos, em comando, melhor visualização da pista em condições de escuridão e baixa visibilidade. Baseado em imagens de sensores infravermelhos transmitidas a head-up ou head-down (dispositivo que permite a vigilância do meio externo, pois contém todas as informações referentes ao voo), os displays foram criados como auxílio para o pouso; entretanto, com o seu desenvolvimento percebeuse sua importância para a segurança de voo como ferramenta de alerta situacional no solo e no ar (10).

O Final Approach Runway Occupancy Signal Sinal de Pista Ocupada durante a Aproximação Final (FAROS) - foi criado para alertar de forma direta a tripulação quanto à possibilidade de ocorrer uma colisão da aeronave por uma incursão em pista. O FAROS utiliza o Precision Approach Path Indicator (PAPI) para avisar aos pilotos, através da emissão de flashes, que há algum tipo de interferência na pista autorizada para pouso. Ele foi resultado do esforço da FAA para atender às recomendações de segurança impostas pela Segurança dos Transportes Nacionais (NTSB) (11).

O Runway Status Lights (RWSL) consiste basicamente em um conjunto de luzes vermelhas instaladas na pista principal do aeroporto e suas interseções, controladas automaticamente por intermédio dos dados de um radar de superfície. Esse sistema é usado com o intuito de proporcionar alerta situacional das condições da pista, informando pilotos e motoristas quando ela está segura ou não para a decolagem, o cruzamento ou o ingresso (12).

Por fim, o Airport Movement Area Safety System (AMASS), um sistema que fornece, ao controle de tráfego, alertas sonoros e visuais dos perigos de uma possível incursão em pista, por meio do processamento dos dados de vigilância do ASDE (Radar de vigilância do aeródromo) e de um sistema automatizado de terminal. O sistema trabalha com dados de posição, velocidade e aceleração das aeronaves em procedimento de pouso e decolagem, e com os dados de aeronaves e veículos no solo, emitindo sinal quando o deslocamento dos alvos indica que haverá comprometimento da segurança operacional no aeroporto (13).

\section{SMS como um meio eficaz de prevenção}

Sabe-se que as principais causas de uma ocorrência de incursão em pista estão diretamente relacionadas às falhas ou aos erros dos pilotos, condutores de veículos, pedestres e controladores de voos. Tais situações de perigo ocorrem em virtude da falta de cumprimento e abreviação das regras que devem ser cumpridas. Por exemplo, a manutenção de última hora no pátio do aeroporto, sem aviso prévio aos controladores, é uma situação que pode implicar um grave perigo para as aeronaves que ali trafegam.

Com a elevada demanda no tráfego aéreo, o crescimento constante do número de operações nos aeroportos e a falta de divulgação sobre as incursões em pista, o Safety Management System - Sistema de Gerenciamento da Segurança (SMS) vem se tornando um dos principais meios para a prevenção de ocorrências de incursões em pista. Trata-se de um sistema que tem como objetivo identificar os fatores de riscos presentes em um aeroporto antes que um acidente venha a se consolidar; busca, com isso, a antecipação das medidas corretivas que vão ter total importância na prevenção.

De acordo com dados analisados para este estudo, os acidentes ocorridos na aviação, em sua maioria, provocam, na população aeronáutica, uma preocupação em cumprir as normas preestabelecidas com mais rigidez e com maior atenção nas operações. Isto é, só depois de ocorrida uma tragédia, os aviadores e as empresas procuram cumprir as regras; o tempo passa e, infelizmente, a tendência é que a mesma situação de displicência volte a ocorrer, fazendo com que muitas operações continuem inseguras.

Assim, o uso do SMS exige a permanente supervisão dos fatores contribuintes e o acompanhamento constante do nível de segurança alcançado. Com ele, o ganho de informações sobre os causadores, as soluções e a divulgação vai ser ampliado e isso é muito positivo. O atual cenário revela que é necessário contemplar esse elemento para, assim, haver a diminuição dessas infelizes ocorrências que podem gerar catástrofes inesperadas. 


\section{Como estão sendo tratadas as incursões em pista no Brasil}

Segundo dados divulgados pelo CENIPA (6), houve cerca de 1.100 incursões em pista nos aeródromos brasileiros, somente nos últimos cinco anos. Esse número deve ser divulgado e, acima de tudo, deve servir de alerta às autoridades aeronáuticas para a necessidade de tomar providências cabíveis com o objetivo de mitigar tais ocorrências. Com o crescimento surpreendente da aviação no Brasil, o movimento de aeronaves nos aeroportos brasileiros terá um elevado aumento, exigindo mais segurança, divulgação, treinamento e cooperação.

As incursões em pista influenciam diretamente a segurança de voo e, com um aumento significativo nas atividades aéreas, como é previsto, haverá também uma expansão significativa nas ocorrências envolvendo incursões em pista. Pesquisas realizadas pelo Comitê Nacional de Segurança da Aviação Civil, do Canadá (Transport Canada), indicam que o aumento de 20\% no número de pousos e decolagens em um aeroporto pode representar um crescimento de até 140\% de probabilidade de riscos de colisões por incursão em pista (14).

Além desses dados, vale enfatizar que sinalização ou marcações inadequadas; projetos de aeroportos complicados; alterações de última hora transmitidas pela torre de controle para uma aeronave em táxi ou decolagem; distração; carga de trabalho elevada; fadiga; falta de treinamento, em geral, para melhorar a qualidade do trabalho realizado por todos os profissionais; déficit na interpretação das condições meteorológicas; falta de familiarização com um aeródromo; e ausência das cartas de aeródromos em mãos também são alguns dos diversos motivos que podem causar um acidente ou incidente com incursão em pista.

Diante dessa situação, a utilização do SMS e de outros recursos da tecnologia, o bom treinamento e a colaboração de pilotos, controladores de tráfego aéreo e motoristas são os principais meios de prevenção de uma calamidade. Estas são atitudes simples, baratas e de grande utilidade para promover a segurança da aviação no Brasil. Também algumas que envolvem mais gastos, como o aumento da consciência de segurança entre todos os usuários do transporte aéreo através de palestras, congressos, minicursos, fóruns de discussão colaborativa para as melhorias sugeridas; o adicionamento de sinalização avançada em uma determinada área do aeroporto que apresente um maior risco à segurança; a coleta de dados, as análises e campanhas de segurança são fundamentais.
Todas essas questões revelam que as incursões em pista, por constituírem um problema grave no atual panorama da aviação brasileira, devem ser mais discutidas pelas autoridades aeronáuticas. A exigência do cumprimento das medidas de prevenção já existentes e a implantação de outras mais eficazes, bem como a sua fiscalização, são necessárias, visto que esse tema não está sendo enfatizado da maneira como deveria e os acidentes vêm se agravando com a maior frota de aeronaves.

Cabe à população aeronáutica divulgar os fatos e cobrar das autoridades aeronáuticas essas providências. Caso as medidas não sejam tomadas de imediato no Brasil, o número de ocorrências envolvendo incursão em pista vai continuar aumentando em níveis devastadores e vão se acentuar os acidentes fatais. Em meio a tanta omissão, é necessário ainda fazer um levantamento de dados, criar um banco de dados e desenvolver uma cultura de segurança para que, assim, os números se tornem menos apavorantes.

\section{Considerações finais}

Incursão em pista é um problema atual e, apesar dos muitos equipamentos que já estão sendo utilizados, acredita-se que ela pode ser mitigada, ou até mesmo eliminada da aviação, através do emprego de mais tecnologias aplicadas a esse setor. Atualmente, em aeródromos de grande movimento, já estão sendo usados vários equipamentos tecnológicos, como alarmes e luzes de aviso para alertar pilotos e controladores de tráfego aéreo quanto às ameaças provocadas por ações operacionais inadequadas, que possam provocar uma incursão em pista. Nesse sentido, são necessários a consciência situacional e o trabalho em equipe, não se pode promover o individualismo e o egoísmo em meio a uma questão tão grave e crescente mundialmente.

Nenhum tipo de condição de risco, que possa levar à ocorrência de incursões em pista, deve ser ignorado, já que a crescente demanda do tráfego aéreo certamente implicará a ocorrência de acidentes mais graves. Portanto, deve-se auxiliar a comunidade aeronáutica, em geral, a lidar de forma mais eficiente e segura com os acidentes e incidentes envolvendo incursão em pista. Todo usuário do cenário da aviação deve ter em mente suas responsabilidades, obrigações, e cumpri-las bem, pois acidentes acontecem em pequenos e grandes aeroportos, sem data e hora marcadas; uma simples falha o consolida.

Com o decorrer do tempo, com os acidentes já ocorridos e, de acordo com estudos feitos, constata-se 
que o principal protagonista das incursões em pista é o próprio homem, sem a boa qualificação de seu trabalho, por exemplo, não adiantam investimentos milionários no sistema de aviação. Todo o movimento de aeronaves, veículos e pessoas, e todos querendo alcançar seus objetivos, em um mesmo aeroporto, são alguns dos motivos para que se tenha um detalhado conhecimento sobre incursão em pista. Entender corretamente as instruções do controle, responder bem a elas e observar o que acontece no local de trabalho são atitudes fundamentais para uma boa consciência situacional.

Também o uso do SMS e de outros equipamentos é fundamental para coletar, analisar e investigar as principais causas de uma incursão em pista. Assim, aprender a reportar os incidentes, por mais simples que sejam, é uma arte. Um bom treinamento para futuros profissionais da aviação, por meio de simuladores e de uma didática adaptada às novas tecnologias, em razão de seu surgimento de forma contínua, bem como o esforço pessoal de aprimoramento nas escolas de formação, devem ser incentivados cada vez mais. Tudo isso com uma finalidade em comum: mais preparo e segurança para lidar com aeronaves cada vez mais avançadas em tecnologia e, consequentemente, complexas.

Um aeroporto novo e complexo para os pilotos, a cabine de uma aeronave cheia de telas e o GPS podem causar distração e agravar uma situação. Espera-se que a dificuldade de adaptação às novas tecnologias e a aceitação delas, a consciência situacional, a coleta de dados, o estudo contínuo e as medidas de prevenção sejam de interesse de todos os profissionais da aviação.

Cabe enfatizar que os esforços em melhorar ou resolver os problemas apontados só terão realmente validade, só serão satisfatórios, se o homem perceber que ele é o primeiro e principal meio de prevenção da segurança de voo e das operações no solo de um aeroporto. Os fatores contribuintes para incursões em pista e para sua prevenção estão sendo espalhados pelo mundo. As autoridades aeronáuticas já têm conhecimento da seriedade de tamanho problema; assim, que as práticas recomendadas e necessárias para mitigá-lo sejam utilizadas o mais rápido possível.

\section{REFERÊNCIAS}

1. Sant'anna I. Perda total. Rio de Janeiro: Objetiva; 2011.

2. ICAO. International Civil Aviation Organization. Manual on the prevention of runway incursions [Internet]. Montreal, Canadá; 2007 [citado em 11 de dezembro 2009]. Disponível em: <http://www.icao.int/fsix/_Library\%5CRunway\%20 Incursion\%20Manualfinal_full_fsix.pdf $>$.

3. EUROCONTROL. Organização Europeia para a Segurança da Navegação Aérea. European action plan for the prevention of runway incursions. Bruxelas, Bélgica; 2006.

5. Cardosi K. Runway safety: it's everybody's business. Washington, EUA: Federal Aviation Administration, Department of Transportation, 2001.

4. Hudson P. Human factors in runway incursion incidents. In: ICAO, RUNWAY SAFETY SEMINAR. University of Leiden, Moscow; 2005 [citado em 13 de janeiro de 2015]. Disponível em: < http://www.icao.int/EURNAT/Other\%20 Meetings\%20Seminars\%20and\%20Workshops/SAFE/ RASMS1/runway_moscow_20051212_pres4.pdf $>$.

6. CENIPA: Centro de prevenção e investigação de acidentes aeronáuticos. ICA 3-2: Programa para Prevenção de Acidentes Aeronáuticos da Aviação Civil Brasileira para 2010. Brasília-DF: Ministério da Defesa do Comando da Aeronáutica; 2010.

7. DECEA: Departamento de Controle do Espaço Aéreo. ICA 63-21: Programa para Prevenção de Ocorrências de Incursão em Pista no ATS. Brasília-DF; 2009.

8. Flight safety foundation. European Air Traffic Controllers Assert Influence to Prevent Runway Incursions. Alexandria, EUA; 2004 [citado em 22 de agosto de 2014]. Disponível em: < http://www.skybrary.aero/bookshelf/ books/261.pdf>.

9. Mcluhan M. Os meios de comunicação como extensões do homem (understanding media). São Paulo-SP: Cultrix; 1964.

10. FAA. Enhanced Flight Visual System (EFVS). Washington; 2008

11. FAA. Operational Evaluation of FAROS: Final Approach Runway Occupancy Signal [Internet]. 2009 [citado em 20 de dezembro 2014]. Disponível em: < http://rwsl.1l.mit.edu/ pdf/FAROS_DFW Pilots_Training_OpEval.pdf $>$.

12. FAA. Runway Status Lights (RWSL): operational, evaluation and experience. Washington; 2009.

13. GAO. Government Accountability Office. Progress on reducing runway incursions impeded by leadership, technology, and other challenges. 2008 [citado em 02 de janeiro de 2015]. Disponível em: < http://www.gao.gov/new. items/d08481t.pdf>.

14. CENIPA: Centro de Prevenção e Investigação de Acidentes Aeronáuticos. In: XIV CURSO DE PREVENÇÃO DE ACIDENTES: FATOR HUMANO. Brasília-DF; 2006.

Correspondence address:

Wilber Campos Fonseca

$<$ wilbercampos@hotmail.com> 